\title{
Molybdenum surface enrichment and release during transpassive dissolution of Ni-based alloys
}

Jeffrey D. Henderson ${ }^{1,+}$, Xuejie $\mathrm{Li}^{2,+}$, David W. Shoesmith ${ }^{1,3}$, James J. Noël1,3 , Kevin Ogle ${ }^{2, *}$

1 Department of Chemistry, Western University, London, ON, N6A 5B7, Canada

2 Chimie-ParisTech, PSL Research University, IRCP-CNRS, 75005, Paris, France.

3 Surface Science Western, Western University, London, ON, N6G 0J3, Canada

* Indicates corresponding author

+ Indicates equal contribution

Graphical abstract

Molybdenum surface enrichment and release during transpassive dissolution of Ni-based alloys

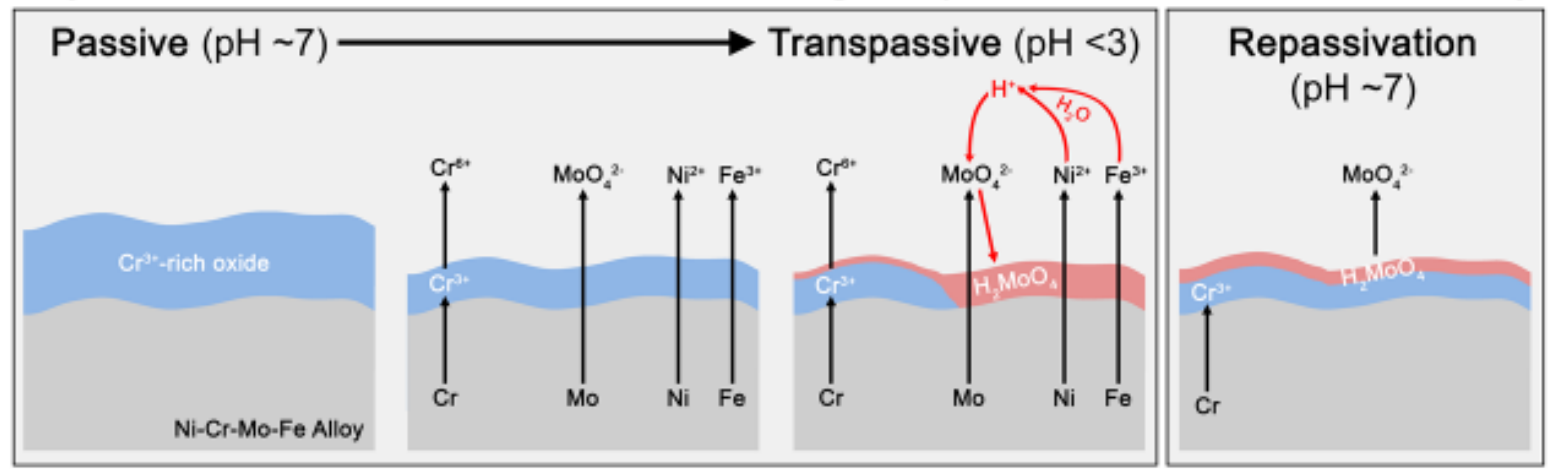

Highlights

- $\mathrm{Ni}, \mathrm{Cr}, \mathrm{Mo}$ and Fe dissolution were monitored as a function of time in the passive and transpassive domain.

- Mo surface enrichment, probably as $\mathrm{H}_{2} \mathrm{MoO}_{4}$, was observed during potentiostatic experiments in the transpassive domain.

- The excess Mo was released into the electrolyte when the potential returned to the passive domain.

- It is proposed that Mo precipitation and redissolution are driven by changes in the local $\mathrm{pH}$.

- This phenomenon, reported here for the first time, may contribute to the positive effect of Mo on repassivation kinetics. 


\section{Abstract}

The role of alloyed Mo during transpassive dissolution of four commercially available Ni-based alloys in neutral chloride solution was investigated by atomic emission spectroelectrochemistry. Timeresolved dissolution rates of $\mathrm{Ni}, \mathrm{Cr}, \mathrm{Mo}$, and Fe were obtained as a function of applied potential. Mo enrichment occurred at the transpassive potentials and redissolved when the potential returned to the passive domain. These results suggest a mechanism of Mo enrichment and release that could play a significant role in repassivation in initially neutral electrolytes such as occurs during crevice corrosion. It is proposed that Mo precipitation and redissolution are driven by local pH changes.

Keywords: Ni-Cr-Mo, Hastelloy, transpassive, repassivation, molybdenum, AESEC

\subsection{Introduction.}

$\mathrm{Ni}$-based alloys are frequently used to replace conventional steels when service conditions become aggressive and high corrosion rates ensue. Applications include, but are not limited to, the nuclear, petrochemical, and chemical processing industries. These alloys, which differ mainly in composition, are continuously being modified to improve corrosion and/or mechanical properties ${ }^{1-2}$. However, successfully tailoring composition to a given application requires the thorough understanding of how individual alloying elements affect behavior. Chromium is, of course, the most significant constituent as concerns corrosion resistance, and its role in passivity has been thoroughly documented ${ }^{3-4}$. The significance of the other alloying elements, such as Fe and Mo, on corrosion resistance is less well understood. These elements may be of critical importance in the transpassive potential domain, where the electrochemical conversion of the $\mathrm{Cr}$ (III) oxide into soluble $\mathrm{Cr}(\mathrm{VI})$ species occurs $^{3,5-6}$, making the $\mathrm{Cr}(\mathrm{III})$ based passive film less stable. This may be problematic for some industrial applications in which the Ni alloy is exposed to electrolytes containing large amounts of oxidizing impurities, resulting in high corrosion potentials $\mathrm{s}^{7-8}$.

Molybdenum, in particular, remains an interesting alloying component, as it is well known to enhance corrosion resistance. For example, in the empirically defined PREN (pitting resistance equivalent number) for both Ni-based alloys and stainless steels, the \%Mo counts $3.3 \mathrm{x}$ the $\% \mathrm{Cr}^{2,6,9}$. Nevertheless, the exact mechanisms by which Mo increases the corrosion resistance remain elusive. Benefits of Mo addition include the suppression of active dissolution and increased resistance to localized corrosion ${ }^{3,10}$. Among the proposed mechanisms, two concepts are frequently discussed. First, Mo has been suggested to concentrate at defect sites of the oxide film, acting as a reinforcement or filler at defect locations in the oxide ${ }^{11-12}$. Second, Mo oxides, found in the outer portion of $\mathrm{Cr}$ dominated oxide films, are believed to provide a cation-selective nature to the oxide film, preventing the ingress of aggressive $\mathrm{Cl}^{-}$ions ${ }^{13-14}$.

The mechanism of passivation for $\mathrm{Fe}-\mathrm{Cr}$ and $\mathrm{Ni}-\mathrm{Cr}$ alloys involves a selective dissolution of $\mathrm{Fe}$ and $\mathrm{Ni}$, leaving behind a $\mathrm{Cr}(\mathrm{III})$ oxide film ${ }^{15-17}$. For austenitic stainless steel, it has been suggested that when the passive film is breached, Mo oxides form a temporary protective film which slows down active dissolution sufficiently to allow the $\mathrm{Cr}$ (III) passive film to reform ${ }^{18}$. This is important in the mechanism of pitting and crevice corrosion in that the local electrolyte conditions may not favor the spontaneous formation of a $\mathrm{Cr}(\mathrm{III})$ oxide film and this temporary protection could be a determining factor in the corrosion resistance.

This temporary protection hypothesis suggests that the release mechanism of Mo could therefore play a critical role in the corrosion resistance of $\mathrm{Cr}$-Mo alloys of $\mathrm{Ni}$ or Fe. At present, studies 
of the effect of Mo have been limited to conventional electrochemistry and ex situ surface analysis. While these studies demonstrated a tendency of Mo to concentrate at the oxide/solution interface, no kinetic information concerning its release and its build-up on the surface have been presented, to our knowledge ${ }^{19-21}$.

In this work, atomic emission spectroelectrochemistry (AESEC) was used to give, for the first time, a quantitative observation of Mo retention and release during the transpassive dissolution of commercial $\mathrm{Ni}-\mathrm{Cr}-\mathrm{Mo}$ alloys. These findings demonstrate that $\mathrm{Mo}$ is enriched the surface during the onset of transpassive dissolution. During repassivation, the surface-enriched Mo was selectively removed. Notably, the degree of Mo enrichment and subsequent dissolution at the surface were found to increase with increasing Fe content of the alloy. This was attributed to the rapid hydrolysis of Fe(III) compared to $\mathrm{Ni}(I I)$, leading to an increased local acidification, which is known to promote the deposition of Mo-species.

\subsection{Experimental}

2.1 Materials

Alloys used in this study were provided by Haynes International (Kokomo, IN, USA) in the form of mill-annealed sheets. Coupons were cut to dimensions of $25 \times 10 \mathrm{~mm}^{2}$ to fit in the requirements of the flow cell. Coupon thickness varied between 5 and $10 \mathrm{~mm}$, based on the thickness of the original sheet. The nominal composition of each alloy, as reported by Haynes International, is provided in Table 1.

Since the analysis of AESEC data relies heavily on the use of accurate compositions, i.e. for normalization purposes, the exact composition of each alloy, determined by glow discharge optical emission spectroscopy (GD-OES), is also included in Table 2. For discussion purposes both compositions (Table $1 \& 2$ ) are included here.

Prior to each measurement, coupons were ground using wet SiC paper, with the final surface preparation using P1200 grit. Coupons were then rinsed with deionized (DI) water $(18.2 \mathrm{M} \Omega \mathrm{cm}$ ), followed by ethanol, and dried in a stream of $\mathrm{N}_{2}$ gas. Careful surface preparation produced reproducible surface conditions and ensured a proper seal between the coupon and flow cell.

Solutions were prepared using reagent grade $\mathrm{NaCl}$ (Carl Roth $\mathrm{GmbH}$ ) and DI water. Standard solutions, used to quantify inductively coupled plasma atomic emission spectrometer (ICP-AES) data, were prepared using aliquots of metal standards (SCP Science) in the experimental electrolyte (1 M $\mathrm{NaCl}$ ). Calibration was performed immediately following each experiment.

\subsection{Electrochemical Measurements}

Electrochemical measurements were made using either a Gamry Reference 600 (for AESEC) or a Biologic VSP potentiostat (conventional electrochemistry). All electrochemical measurements were carried out in a custom-built PTFE flow cell designed for use with the AESEC setup. The flow cell, briefly summarized below, has been extensively detailed elsewhere ${ }^{22-23}$. The working electrode (WE) was affixed to the flow cell with an exposed surface area of $1 \mathrm{~cm}^{2}$ by the application of a fixed pneumatic pressure against an O-ring. A second compartment, isolated from the flow cell compartment by a porous membrane, housed the reference (RE) and counter electrodes (CE). A saturated $\mathrm{Ag} / \mathrm{AgCl}$ electrode $(-0.197 \mathrm{~V}$ vs $\mathrm{SHE})$ served as the $\mathrm{RE}$ against which all potentials were 
measured. A platinum flag was used as the CE. All electrochemical experiments described herein were repeated at least twice.

The temperature was maintained at approximately $75^{\circ} \mathrm{C}$ by placing the experimental electrolyte in an isothermal circulating bath. During the experimental procedure, electrolyte introduced to the flow cell was drawn directly from the reservoir housed within the isothermal bath. Additionally, a hollowed Cu heating disk, connected to the circulating component of the isothermal bath, was fixed behind the WE. Together, this maintained the temperature of the WE and electrolyte at approximately $75^{\circ} \mathrm{C}$ during all measurements. The flow rate was controlled using the built-in peristaltic pump of the ICP-AES instrument. Prior to each experiment the flow rate was calibrated to be approximately $2.75 \mathrm{~mL} \mathrm{~min}^{-1}$.

Cyclic polarization experiments were initiated $0.100 \mathrm{~V} v \mathrm{Ag} / \mathrm{AgCl}$ below the corrosion potential and scanned positively at a scan rate of $0.5 \mathrm{mV} \mathrm{s}^{-1}$, until a potential of $1 \mathrm{~V} \mathrm{vs} \mathrm{Ag} / \mathrm{AgCl}$ was reached. The scan was then reversed, and the potential scanned negatively until it reached the initial $E_{j=0}$. Separate potentiostatic experiments were conducted using three potential steps. Initially, samples were held in the passive region $0.300 \mathrm{~V}$ vs $\mathrm{Ag} / \mathrm{AgCl}$ for $5 \mathrm{~min}$. Subsequently, samples were brought into the transpassive domain $1.00 \mathrm{~V}$ vs $\mathrm{Ag} / \mathrm{AgCl}$ for a period of 1,2 , or 4 min, indicated for each experiment. Finally, the return to the initial applied potential $0.300 \mathrm{~V} v \mathrm{Ag} / \mathrm{AgCl}$ caused the sample to repassivate.

\subsection{AESEC Measurements and Data Treatment}

Details regarding the data acquisition and treatment have been described by Ogle et al. ${ }^{22}$. Briefly, the downstream positioning of the ICP-AES instrument, an Ultima $2 \mathrm{C}$ spectrometer (Horiba Jobin-Yvon, France), allows for the detection of cations released from the WE in real-time. A Burgener PEEK Mira Mist ${ }^{\circledR}$ Nebulizer (Horiba Jobin-Yvon, France) was used to introduce electrolyte leaving the flowcell into the ICP. The resultant aerosol enters a $40.68 \mathrm{MHz}$ inductively coupled Ar plasma, operating at $1.2 \mathrm{~kW}$. Independent monochromator and polychromator optics were used to monitor emission lines from the ICP torch. The monochromator was used for a single element with high spectral resolution, in this case Mo, while the polychromator was used to simultaneously detect other elements of interest. Emission lines used for the elements of interest and their respective limits of detection are summarized in Table 3 . The detection limit $\left(\mathrm{C}_{3 \sigma}\right)$ was calculated according to eqn. 1 , where $\sigma_{\mathrm{B}}$ is the standard deviation of the background signal and $\alpha$ the sensitivity factor determined from the calibration standards.

$$
C_{3 \sigma}=3 \frac{\sigma_{B}}{\alpha}
$$

Upon completion of AESEC experiments, instantaneous emission intensities for each metal were converted into instantaneous concentrations $\left(C_{M}\right)$ by standard calibration. $C_{M}$ values were then converted into instantaneous dissolution rates $\left(v_{M}\right)$ according to eqn. 2 , where $f$ is the flow rate and $A$ the surface area:

$$
v_{M}=f \frac{C_{M}}{A}
$$

Congruent and incongruent dissolution behaviour were distinguished by comparing the composition of the electrolyte to that of the bulk material. This was done by normalizing individual dissolution rates against that of the bulk alloying element, $\mathrm{Ni}$, according to eqn. 3 . 


$$
v_{M}^{\prime}=\left(X_{N i} /_{M}\right) v_{M}
$$

where $X_{M}$ is the mass fraction of element $M$ as determined by GD-OES (Table 2). Perfect congruent dissolution occurs when $v_{M}^{\prime}=v_{N i}$, i.e., the two are dissolving at equal rates relative to the bulk composition. If $v_{M}^{\prime}>v_{N i}$, it implies the selective dissolution of alloying element $M$ in comparison to the bulk alloying element, $\mathrm{Ni}$. In contrast, $v_{\mathrm{M}}^{\prime}<v_{\mathrm{Ni}}$ implies that excess $\mathrm{M}$ is concentrating at the surface. The quantity of excess $M, Q_{M}$, may be determined by mass balance as:

$$
Q_{M}=\int_{0}^{t}\left(\left(X_{M} /_{X_{N i}}\right) v_{N i}-v_{M}\right) d t
$$

The elemental current density or metal $\mathrm{M}, \mathrm{j}_{\mathrm{M}}$, was determined by conversion of the corresponding instantaneous dissolution rate $\left(\mathrm{V}_{\mathrm{M}}\right)$ according to equation 5 :

$$
j_{M}=\frac{v_{M} F n}{m}
$$

where $\mathrm{F}$ is Faraday's constant, $\mathrm{m}$ the molar mass of metal $\mathrm{M}$ and $\mathrm{n}$ the number of electrons transferred in the oxidation reaction of metal $\mathrm{M}$. The later assumes that the oxidation state of the dissolved $\mathrm{M}$ is known or may be surmised from equilibrium calculations. This is a formal definition only, as dissolution may occur via non-faradaic processes such as the dissolution of oxide films.

\subsection{Results}

\subsection{Cyclic polarization}

The polarization behavior of BC-1, C-22, and G-35, is shown in Fig. 1 A and that of G-30, in Fig. 1B. All four alloys exhibited passive behavior, with the alloys of higher $\mathrm{Cr}$ content having higher potentials of zero current, $\mathrm{E}_{\mathrm{j}=0}$, and lower passive current densities, $\mathrm{j}_{\text {pass, }}$, consistent with previous studies $^{5}$. Table 4 summarizes the values of $\mathrm{E}_{\mathrm{j}=0}$ and $\mathrm{j}_{\text {pass }}$ for the different alloys. The anodic branch of the polarization curves may be divided into three potential domains: (1) a passive domain from $\mathrm{E}_{\mathrm{j}=0}$ to approximately $0.300 \mathrm{~V}$ vs $\mathrm{Ag} / \mathrm{AgCl},(2)$ a second passive domain starting near $0.300 \mathrm{~V} \mathrm{vs} \mathrm{Ag} / \mathrm{AgCl}$, indicated by an increase in the anodic current followed by a current plateau; and (3) the transpassive domain, indicated by a steady increase in the current, beginning at approximately $0.600 \mathrm{~V}$ for alloys $\mathrm{BC}-1, \mathrm{C}-22$, and $\mathrm{G}-35$, and at $0.800 \mathrm{~V}$ vs $\mathrm{Ag} / \mathrm{AgCl}$ for alloy $\mathrm{G}-30$. The extended passive region of G-30 is believed to be the result of Fe(III) oxide stability at high potentials ${ }^{24}$.

Return scans showed a ready repassivation for alloys BC-1, C-22, and G-35, without significant hysteresis. This was indicated by the current density retracing the forward scan until ultimately achieving values lower than those recorded during the forward scan. In all cases, $\mathrm{E}_{\mathrm{j}=0}$ was shifted positive relative to its value on the forward scan. Interestingly, all three alloys exhibited approximately the same $E_{j=0}$ values on the reverse scan. The decreased current densities observed on the reverse scan have been attributed to the repair of the $\mathrm{Cr}(\mathrm{III})$ barrier layer ${ }^{25}$.

The reverse scan on alloy G-30 (Fig. 1B) showed an interesting irreproducibility: It was frequently found to have hysteresis or a complete loss of I-E relationship, as shown by the solid and dotted curves, respectively. Both behaviors suggest the onset of localized corrosion processes, with one eventually repassivating (solid line) and the other becoming self-sustaining (dotted line). The process occurring during the self-sustaining localized process was confirmed to be crevice corrosion 
by optical observations of damage along the impression of the O-ring. Since crevice corrosion itself is not the focus of the present work, only AESEC data in which active crevice corrosion was not observed are discussed.

Within the passive region, no metal cations were detected by ICP-AES. This was attributed to the low corrosion rates afforded by the $\mathrm{Cr}$-rich oxide film present in this region. Only at transpassive potentials (i.e. the breakdown of the secondary passive region) were cations detected, approximately $0.600 \mathrm{~V}$ for alloys $\mathrm{BC}-1, \mathrm{C}-22$, and $\mathrm{G}-35$, and $0.800 \mathrm{~V} \mathrm{vs} \mathrm{Ag} / \mathrm{AgCl}$ for alloy $\mathrm{G}-30$. Polarization in the transpassive domain led to an exponential increase in dissolution rates as a function of potential. The resultant AESEC data for cyclic polarization experiments is shown in Fig. 2. All alloys demonstrate patterns of incongruent dissolution, indicated by $v_{M}^{\prime} \neq v_{N i}$. Comparison of normalized rates reveals the decreased dissolution rate of $\mathrm{Cr}, \mathrm{Mo}$, and $\mathrm{Fe}$, relative to $\mathrm{Ni}$, suggesting the enrichment of these elements at the electrode surface. In other words, Ni was selectively removed from the oxide during transpassive dissolution while other alloying elements were enriched, at least to some extent.

Of particular interest in Fig. 2, and the focus of this article, is the unusual behavior of Mo during the reverse scan. Interestingly, repassivation resulted in $v_{M o}^{\prime}$ becoming larger than $v_{\mathrm{Ni}}$, suggesting the selective dissolution of Mo. While repassivation resulted in receding values of $v_{\mathrm{Ni}}, v^{\prime} \mathrm{Cr}_{\mathrm{r}}$ and $v_{\mathrm{Fe}}^{\prime}$, the elevated rates of Mo dissolution persisted for some time following repassivation. While Mo appears to be initially retained at the surface during transpassive dissolution, it is subsequently released during repassivation. This feature is particularly pronounced for alloy $\mathrm{G}-30$, and a thorough discussion of normalized data is conducted below for potentiostatic experiments.

\subsection{Potentiostatic Polarization}

To better quantify the kinetics and mechanism of Mo retention and dissolution, a four-step potentiostatic experiment was performed: (1) the WE was held in the passive region $(0.300 \mathrm{~V}$ vs $\mathrm{Ag} / \mathrm{AgCl})$ for $300 \mathrm{~s}$ to obtain a steady-state passive film; (2) the potential was then stepped to the transpassive domain (1.00 V vs Ag/AgCl) for $120 \mathrm{~s}$; (3) the WE was returned to the passive region, and (4) finally released to open-circuit. The resulting data, expressed as normalized dissolution rates and elemental currents, are presented in Fig. 3 and 4, respectively.

In the analysis of the normalized dissolution data, the observations are similar to those made during cyclic experiments. Notably, potentiostatic experiments avoided complications arising from localized processes apparent in potentiodynamic experiments. While samples were held in the passive region, step 1, no metal cations were detected by ICP-AES. Following the application of the transpassive potential, step 2, all alloys demonstrated a surge of metal dissolution. The relative intensities of the normalized dissolution rates were similar to those found during cyclic experiments. In all cases, $\mathrm{Ni}$ was found to be the dominant cation released from the $\mathrm{WE}$, while $\mathrm{Cr}$, Mo, and Fe were apparently retained, to some extent, at the surface.Of the alloying elements monitored, Mo showed the greatest tendency of surface enrichment. Shown in Fig. 3, during repassivation all alloys exhibited the selective dissolution of Mo species, interpreted as a subsequent release of surface enriched Mo. The extent of Mo retention and release was greatest for alloy G-30 and quite significant for C- 22 . Interestingly, this process did not correlate directly with the Mo content of the alloy.

Additionally, the stoichiometry of dissolution was monitored with ICP-AES during potentiostatic experiments. To directly compare the elemental current densities, $\mathrm{j}_{\mathrm{M}}$, to the electrical current density, $\mathrm{j}_{\mathrm{e}}$, a convolution procedure was carried out. Details of this convolution have been published previously ${ }^{22}$. Briefly, convolution involves correcting the instantaneous current density, $\mathrm{j}_{\mathrm{e}}$ for the distribution of residence times in the flow cell. In this way, the elemental current densities, $\mathrm{j}_{\mathrm{M}}$, may be compared directly with the convoluted electrical current density, je ${ }^{*}$. As shown in Fig. 4, 
significant currents were detected only after the application of the transpassive potential. The convoluted current density recorded by the potentiostat, $\mathrm{j}^{*}$, the current contributed by individual alloying elements, $\mathrm{j}_{\mathrm{M}}$, and the sum current from all elemental currents, $\mathrm{j}_{\Sigma}$, are compared in Fig. 4. Values of $\mathrm{j}_{\mathrm{M}}$ were calculated according to the following oxidation states: $\mathrm{Ni}(\mathrm{II}), \mathrm{Cr}(\mathrm{VI}), \mathrm{Mo}(\mathrm{VI})$, and $\mathrm{Fe}(\mathrm{III})$. Oxidation state information was based on both thermodynamics as well as findings in the literature ${ }^{20,24}$. Since dissolution prior to the transpassive domain was negligible, oxidation states were selected based on the environment for transpassive dissolution.

Using the dissolution rates and elemental currents obtained during potentiostatic experiments, information on alloy composition and faradaic yield was extracted. A summary of this information is detailed in Table 5. Using elemental dissolution rates, the total dissolved metal was used to determine a relative alloy composition for comparison to the compositions provided by Haynes International and GD-OES analysis, Tables $1 \& 2$ respectively. Since in the ICP-AES data, only $\mathrm{Ni}, \mathrm{Cr}, \mathrm{Mo}$, and Fe were quantified, the compositions provided by Haynes International and by GDOES analysis were reweighted for a valid comparison. As shown in Table 5, the reweighted compositions are in agreeance with only minor discrepancies. Since AESEC data shows dissolution occurs incongruently, the alloy composition determined by ICP-AES is expected to be affected by surface enrichment processes. For example, the surface enrichment of $\mathrm{Cr}$ - species, highlighted in AESEC data above, leads to a consistently lower $\mathrm{Cr}$ content in ICP-AES analysis. Important for the upcoming discussion section is the low amount of Fe detected for alloys BC-1 and G-35 by both GDOES and ICP-AES. As reported by Haynes, these alloys are expected to contain a maximum concentration of $2 \% \mathrm{Fe}$, however, based on both GD-OES and ICP-AES data presented here, the Fe content is in fact much lower, approximately $0.6 \%$.

In addition to comparing the re-weighted alloy compositions, faradaic yields were determined by the direct comparison of $\mathrm{j}_{\mathrm{e}}{ }^{*}$ and $\mathrm{j}_{\Sigma}$ from Fig 4 . The values obtained for alloys BC-1, C-22, G-35, and G-30 are shown in Table 5. The average faradaic yield, $98.0 \%$, implies that the metallic dissolution measured by ICP-AES is in good agreement with the instantaneous current densities recorded by the potentiostat. However, minor discrepancies in faradaic yields may be the result of additional anodic processes undetected by the ICP-AES, e.g. $\mathrm{O}_{2}$ evolution or oxide formation.

\subsection{Mo Enrichment}

As detailed in the discussion of Fig. 3, the high degree of Mo-enrichment observed for alloy G30, made this alloy ideal for the further study of enrichment/dissolution phenomenon. Additional experiments were conducted as a function of time spent in the transpassive domain, shown in Fig. 5. Generally, as time spent in the transpassive domain increased, so did the signal corresponding to Mo dissolution during repassivation.

Direct comparison of the enrichment and dissolution of Mo is possible by considering the excess $\mathrm{Mo}, \mathrm{Q}_{\mathrm{Mo}}$, during steps 2 and 3, enrichment and dissolution, respectively. The calculation of excess Mo was made according to eqn. 4 . In step 2, the degree of enrichment is visualized as the difference between the integrals of $\mathrm{Ni}$ and Mo dissolution rates. In step 3, the dissolution of surfaceenriched $\mathrm{Mo}$ is the difference between Mo and Ni dissolution rates. For clarity, the regions considered as enrichment and dissolution are graphically depicted in Fig. 6A.

Values corresponding to enrichment and dissolution are compared in Fig. 6B as a function of time polarized in the transpassive region. The amount of Mo-enrichment was found to be proportional to the time spent in the transpassive region. The dissolution process followed a similar relationship; however, it was consistently lower than the degree of enrichment. Comparison of the two values of $\mathrm{Q}_{\mathrm{Mo}}$ yields a percent difference of between 40.2 and $56.8 \%$. 
Discrepancy between these values suggests that the surface-enriched Mo species are not completely removed during repassivation. This implies that previous studies, which demonstrated enrichment of Mo in the oxide following transpassive polarization, have likely underestimated the extent of Mo-enrichment during transpassive dissolution. In such experiments, immediately following the application of a transpassive potential, the relaxation of the WE to a passive potential and subsequent repassivation can be expected to initiate the release of Mo species. This process is anticipated to occur rapidly prior to the removal of the WE from solution.

\subsection{Discussion}

These results represent the first real-time quantitative measurement of the Mo enrichment during transpassive dissolution and its release during the return to the passive state. Obviously, this observation would lend support to the temporary protection hypothesis described in the introduction. When an oxide is compromised, either due to transpassive dissolution or modification in solution chemistry (i.e. pit or crevice), Mo oxides should precipitate on the surface. As the exposed material repassivates, these Mo-rich oxides would dissolve.

It is reasonable to suppose that the enrichment/release mechanism is triggered by changes in the local $\mathrm{pH}$. It is well known that Mo oxides precipitate at low $\mathrm{pH}$, as shown in the equilibrium calculations of Fig. 7, and a significant decrease in $\mathrm{pH}$ may be associated with the high rate of metal dissolution anticipated during transpassive dissolution. Highlighted in Fig.7 are the experimentally determined $\mathrm{pH}$ values for the initial solution ( 7.4) and the solution expelled during transpassive dissolution. Since in situ $\mathrm{pH}$ measurements were not available in the current flow cell design, downstream collection of transpassive solution was subject to diffusion processes and therefore, experimentally measured values ( 3-4) are expected to over-estimate the true $\mathrm{pH}$ at the corroding surface. The idea that this process is $\mathrm{pH}$ dependent is supported by the fact that the largest Mo retention was associated with the alloy with the highest Fe-content. In particular, Fe(III) cations are expected to undergo a more extensive hydrolysis as compared to $\mathrm{Ni}(\mathrm{II})^{24,26}$, resulting in a lower $\mathrm{pH}$. The role of Fe content on this behaviour is further supported by the fact that $\mathrm{C}-22$, containing $3 \% \mathrm{Fe}$, has larger amounts of retained Mo, compared to BC-1 and G-35, which contain at most $\sim 0.6 \% \mathrm{Fe}$, based on both GD-OES and ICP-AES analysis. Nevertheless, the data presented here are only suggestive as to the role of Fe.

In summary of the AESEC results, a graphical illustration of the enrichment / release process is presented in Fig. 8. While the potential is in the passive region, a passive oxide, known to be rich in $\mathrm{Cr}(\mathrm{III})^{3}$, covers the surface and limits the dissolution of the underlying substrate. However, as the system is brought into the transpassive domain, the electrochemical conversion of $\mathrm{Cr}(\mathrm{III})$ to $\mathrm{Cr}(\mathrm{VI})$ results in the destruction of this protective oxide. As a result, cations begin to be released from the metallic substrate into solution. The ensuing hydrolysis reactions lead to a drop in local $\mathrm{pH}$ and the deposition of Mo-rich corrosion products, which are insoluble under acidic conditions (Fig. 7). When the system is returned to the passive region, the reestablishment of the protective oxide, again, limits dissolution and allows the previously developed $\mathrm{pH}$ gradient at the surface to dissipate. The return to the initial $\mathrm{pH}(\sim 7)$ results in the increased solubility of the Mo-rich products and therefore their release from the surface.

This enrichment may play an important role in the repassivation of the material. While the work presented here measures only the degree of enrichment / release and does not attempt to assess its effect on passivity, it is the first account of this dynamic process. Other investigations have shown that under transpassive conditions Mo concentrates in the outer portion of the oxide film ${ }^{19-20 \text {, }}$ 
27. However, as in the cyclic polarization experiments, repassivation resulted in a release of at least a portion of the surface-enriched Mo. The ex situ methodology employed in previous investigations has prevented the observation of this dynamic process.

The process of Mo deposition at low $\mathrm{pH}$ has been extensively studied in the context of crevice corrosion ${ }^{28-34}$. Shan and Payer demonstrated that Mo-rich corrosion products deposit as solid species within the acidified crevice, while species of $\mathrm{Ni}, \mathrm{Cr}$, and $\mathrm{Fe}$ are transported outside of the acidified environment before depositing ${ }^{28}$. The Mo-rich corrosion products found to deposit within the crevice were later characterized by Jakupi et al. by energy dispersive X-ray spectroscopy (EDX) and Raman spectroscopy ${ }^{31}$. While thermodynamics would suggest the formation of $\mathrm{MoO}_{3}$, their findings suggest the formation of polymeric molybdates, including $\mathrm{Mo}_{7} \mathrm{O}_{24}{ }^{6-}$ and $\mathrm{Mo}_{8} \mathrm{O}_{26}{ }^{4-}$, under the acidic conditions present during crevice corrosion.

The occasional observation of crevice corrosion on the G-30 alloy is interesting, and the ability to observe this may represent another line of research for the future. Unfortunately, we were not able to identify the reasons why crevice corrosion was observed in some circumstances and not in others. Previous work has demonstrated that, compared to C-22 and BC-1, alloy G-30 is particularly susceptible to crevice corrosion in hot concentrated chloride solutions ${ }^{33}$. In general, the initiation of crevice corrosion is random and depends on many variables including solution chemistry, crevice geometry, and the ensuing damage morphology. An extensive discussion on the factors involved during the crevice corrosion of $\mathrm{Ni}-\mathrm{Cr}-\mathrm{Mo}$ alloys can be found in a recent review by Carranza and Rodríguez ${ }^{35}$.

\subsection{Conclusions}

For the first time, the dynamic behaviour of Mo during the transpassive dissolution of $\mathrm{Ni}-\mathrm{Cr}$ Mo alloys has been explored using the operando measurement afforded by AESEC. Alloying additions of $\mathrm{Cr}$, Mo, and $\mathrm{Fe}$ appear to be retained on the alloy surface, compared to $\mathrm{Ni}$, during transpassive dissolution. Immediately following repassivation, the Mo species enriched during transpassive dissolution were released from the surface, while the enriched $\mathrm{Cr}$ and Fe were not. As the time spent in the transpassive region increased, so did the enrichment in Mo surface species.

The dual phenomena of transpassive Mo-enrichment and dissolution were found to be particularly pronounced on the high Fe-containing alloy, Hastelloy G-30. This was attributed to the increased local acidification due to the release of rapidly hydrolyzed $\mathrm{Fe}(\mathrm{III})$. Decreased $\mathrm{pH}$ has been extensively linked to the deposition of Mo-rich corrosion product, especially in the context of crevice corrosion.

\section{Acknowledgments}

Financial support was provided by NSERC (Western University). All Hastelloy materials used in this study were provided by Haynes International. Author X.L. acknowledges the financial support of the Chinese Scholarship Council (CSC). Author J.D.H. acknowledges the financial support of the ECS H. H. Uhlig Summer Fellowship. In addition, J.D.H. thanks the opportunity provided by NSERC CGSD/MSFSS and the Department of Chemistry (ASPIRE) at Western University. 


\section{References}

1. Agarwal, D. C.; Klower, J., Nickel base alloys: Corrosion challenges in the new millennium. In CORROSION 2001, NACE: 2001.

2. Klapper, H. S.; Zadorozne, N. S.; Rebak, R. B., Localized Corrosion Characteristics of Nickel Alloys: A Review. Acta Metallurgica Sinica (English Letters) 2017, 30 (4), 296-305.

3. Mishra, A.; Shoesmith, D. W.; Manning, P., Materials Selection for Use in Concentrated Hydrochloric Acid. Corrosion 2017, 73 (1), 68-76.

4. Lutton, K.; Gusieva, K.; Ott, N.; Birbilis, N.; Scully, J. R., Understanding multi-element alloy passivation in acidic solutions using operando methods. Electrochemistry Communications 2017, 80, 44-47.

5. Hayes, J. R.; Gray, J. J.; Szmodis, A. W.; Orme, C. A., Influence of Chromium and Molybdenum on the Corrosion of Nickel-Based Alloys. Corrosion Science 2006, 62 (6), 491-500.

6. Zadorozne, N. S.; Giordano, C. M.; Rodriguez, M. A.; Carranza, R. M.; Rebak, R. B., Crevice corrosion kinetics of nickel alloys bearing chromium and molybdenum. Electrochimica Acta 2012, 76, 94-101.

7. Laurent, B.; Gruet, N.; Gwinner, B.; Miserque, F.; Rousseau, K.; Ogle, K., The kinetics of transpassive dissolution chemistry of stainless steels in nitric acid: The impact of Si. Electrochimica Acta 2017, 258, 653-661.

8. Fauvet, P., Nuclear corrosion science and engineering, 679. Woodhead Publishing, Cambridge: 2012.

9. Lindgren, M.; Huttunen-Saarivirta, E.; Peltola, H.; Romu, J.; Sarikka, T.; Hänninen, H.; Pohjanne, P., Crevice Corrosion of Stainless Steels 904L, 2205, and 2507 in High-Temperature Sulfuric Acid Solution Containing Chlorides: Influence of Metal Cations. Corrosion 2018, 74 (2), 225-240.

10. Hashimoto, K.; Asami, K.; Kawashima, A.; Habazaki, H.; Akiyama, E., The role of corrosionresistant alloying elements in passivity. Corrosion Science 2007, 49, 42-52.

11. Newman, R., The dissolution and passivation kinetics of stainless alloys containing molybdenum (Part I). Corrosion Science 1985, 25 (5), 331-339.

12. Maurice, V.; Peng, H.; Klein, L. H.; Seyeux, A.; Zanna, S.; Marcus, P., Effects of molybdenum on the composition and nanoscale morphology of passivated austenitic stainless steel surfaces. Faraday Discussions 2015, 180, 151-170.

13. Clayton, C. R.; Lu, Y. C., A Bipolar Model of the Passivity of Stainless Steel: The Role of Mo Addition. Journal of The Electochemical Society 1986, 133 (12), 2465-2473.

14. Tomio, A.; Sagara, M.; Doi, T.; Amaya, H.; Otsuka, N.; Kudo, T., Role of alloyed molybdenum on corrosion resistance of austenitic $\mathrm{Ni}-\mathrm{Cr}-\mathrm{Mo}-\mathrm{Fe}$ alloys in $\mathrm{H} 2 \mathrm{~S}-\mathrm{Cl}$ - environments. Corrosion Science 2015, 98, 391-398.

15. Machet, A.; Galtayries, A.; Zanna, S.; Klein, L.; Maurice, V.; Jolivet, P.; Foucault, M.; Combrade, P.; Scott, P.; Marcus, P., XPS and STM study of the growth and structure of passive films in high temperature water on a nickel-base alloy. Electrochimica Acta 2004, 49, 3957-3964.

16. Ogle, K.; Mokaddem, M.; Volovitch, P., Atomic emission spectroelectrochemistry applied to dealloying phenomena II. Selective dissolution of iron and chromium during active-passive cycles of an austenitic stainless steel. Electrochimica Acta 2010, 55, 913-921.

17. Olsson, C.-O. A.; Landolt, D., Passive films on stainless steels - chemistry, structure and growth. Electrochimica Acta 2003, 48, 1093-1104.

18. Hashimoto, K.; Asami, K.; Teramoto, K., An X-ray photo-electron spectroscopic study on the role of molybdenum in increasing the corrosion resistance of ferritic stainless steel in $\mathrm{HCl}$. Corrosion Science 1979, 19, 3-14.

19. Zhang, X.; Shoesmith, D. W., Influence of temperature on passive film properties on $\mathrm{Ni}-\mathrm{Cr}-$ Mo Alloy C-2000. Corrosion Science 2013, 76, 424-431.

20. Zhang, X.; Zagidulin, D.; Shoesmith, D. W., Characterization of film properties on the Ni Cr Mo Alloy C-2000. Electrochimica Acta 2013, 89, 814-822. 
21. Lloyd, A. C.; Noël, J. J.; McIntyre, S.; Shoesmith, D. W., Cr, Mo and W alloying additions in Ni and their effect on passivity. Electrochimica Acta 2004, 49, 3015-3027.

22. Ogle, K.; Weber, S., Anodic Dissolution of 304 Stainless Steel Using Atomic Emission Spectroelectrochemistry. Journal of The Electochemical Society 2000, 147 (5), 1770-1780.

23. Shkirskiy, V.; Maciel, P.; Deconinck, J.; Ogle, K., On The Time Resolution of the Atomic Emission Spectroelectrochemistry Method. Journal of The Electochemical Society 2016, 163 (3), C37-C44.

24. Pourbaix, M., Atlas of electrochemical equilibria in aqueous solutions. Pergamon Press: Oxford; New York, 1966.

25. Ebrahimi, N.; Beiesinger, M. C.; Shoesmith, D. W.; Noël, J. J., The influence of chromium and molybdenum on the repassivation of nickel-chromium-molybdenum alloys in saline solutions. Surface and Interface Analysis 2017, 49, 1359-1365.

26. Baes, C. F., Jr.; Mesmer, R. E., The hydrolysis of cations. Wiley Interscience Division: New York, 1976.

27. Yang, B.; Li, J.; Gong, X.; Nie, Y.; Li, Y., Effects of $\mathrm{Cu}$ addition on the corrosion behavior of NiCoCrMo alloys in neutral chloride solution. RSC Advances 2017, 7, 40779-40790.

28. Shan, X.; Payer, J. H., Characterization of the Corrosion Products of Crevice Corroded Alloy 22. Journal of The Electochemical Society 2009, 156 (9), C313-C321.

29. Ebrahimi, N.; Noël, J. J.; Rodriguez, M. A.; Shoesmith, D. W., The self-sustaining propagation of crevice corrosion on the hybrid BC1 Ni-Cr-Mo alloy in hot saline solutions. Corrosion Science 2016, 105, 58-67.

30. Mishra, A. K.; Shoesmith, D. W., Effect of Alloying Elements on Crevice Corrosion Inhibition of Nickel-Chromium-Molybdenum-Tungsten Alloys Under Aggressive Conditions: An Electrochemical Study. Corrosion Science 2014, 70 (7), 721-730.

31. Jakupi, P.; Wang, F.; Noël, J. J.; Shoesmith, D. W., Corrosion product analysis on crevice corroded Alloy-22 specimens. Corrosion Science 2011, 53, 1670-1679.

32. Ebrahimi, N.; Jakupi, P.; Noël, J. J.; Shoesmith, D. W., The Role of Alloying Elements on the Crevice Corrosion Behavior of Ni-Cr-Mo Alloys. Corrosion 2015, 71 (12), 1441-1451.

33. Henderson, J. D.; Ebrahimi, N.; Dehnavi, V.; Guo, M.; Shoesmith, D. W.; Noël, J. J., The Role of Internal Cathodic Support during the Crevice Corrosion of Ni-Cr-Mo Alloys. Electrochimica Acta 2018, $283,1600-1608$.

34. Lillard, R. S.; Jurinski, M. P.; Scully, J. R., Crevice Corrosion of Alloy 625 in Chlorinated ASTM Artificial Ocean Water. Corrosion Science 1994, 50 (4), 251-265.

35. Carranza, R. M.; Rodriguez, M. A., Crevice corrosion of nickel-based alloys considered as engineering barriers of geological repositories. Materials Degradation 2017, 1, 9. 
Figure 1. (A) Cyclic polarization behaviour of alloy (A) BC-1, C-22, G-35, and (B) G-30 in $1 \mathrm{M} \mathrm{NaCl}$ at $75^{\circ} \mathrm{C}$
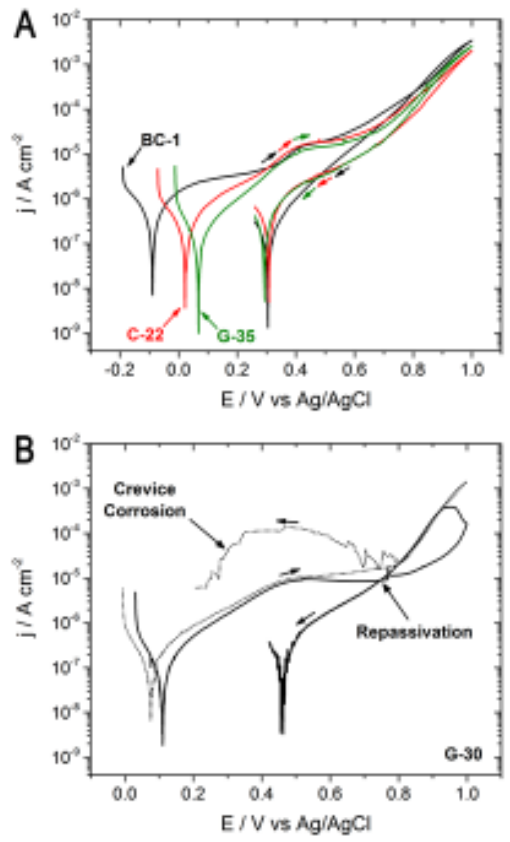
Figure 2. Normalized dissolution rates of alloys BC-1, C-22, G-35, and G-30, during cyclic polarization experiments in $1 \mathrm{M} \mathrm{NaCl}$ at $75^{\circ} \mathrm{C}$. All dissolution rates are normalized against the bulk material, $\mathrm{Ni}$.
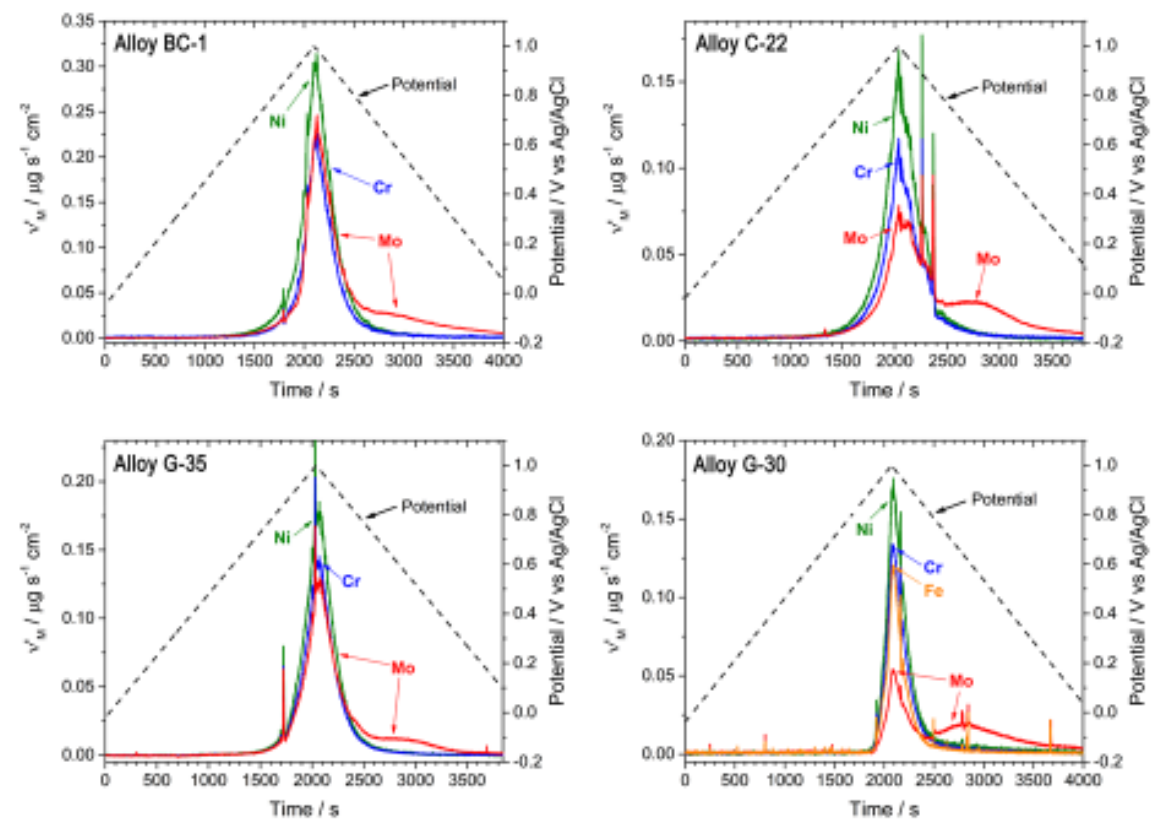
Figure 3. Normalized dissolution rates of alloys BC-1, C-22, G-35, and G-30, during potentiostatic polarization experiments in $1 \mathrm{M} \mathrm{NaCl}$ at $75^{\circ} \mathrm{C}$. All dissolution rates are normalized against the bulk material, $\mathrm{Ni}$
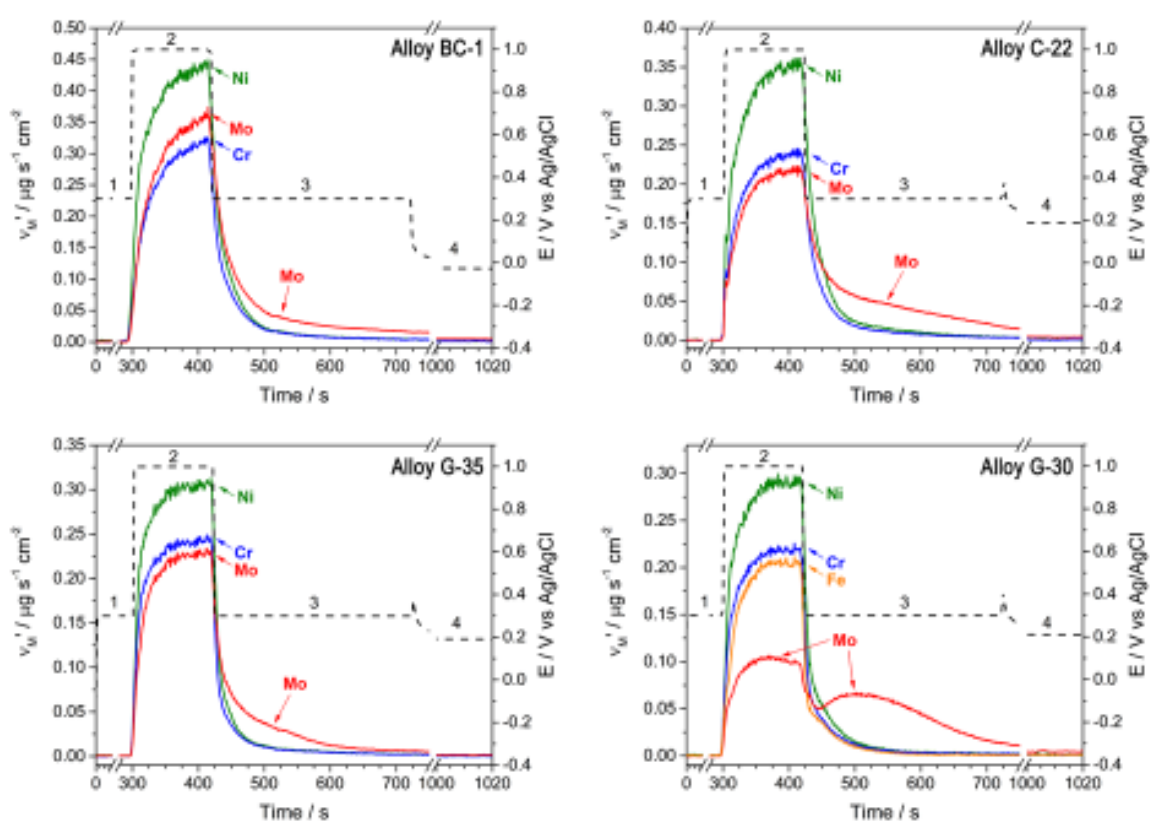
Figure 4. Instantaneous elemental, $\mathrm{j}_{\mathrm{M}}$, sum, $\mathrm{j}_{\Sigma}$, and convoluted electrochemical current, $\mathrm{j}_{\mathrm{e}}{ }^{*}$, for potentiostatic polarization experiments in $1 \mathrm{M} \mathrm{NaCl}$ at $75^{\circ} \mathrm{C}$.
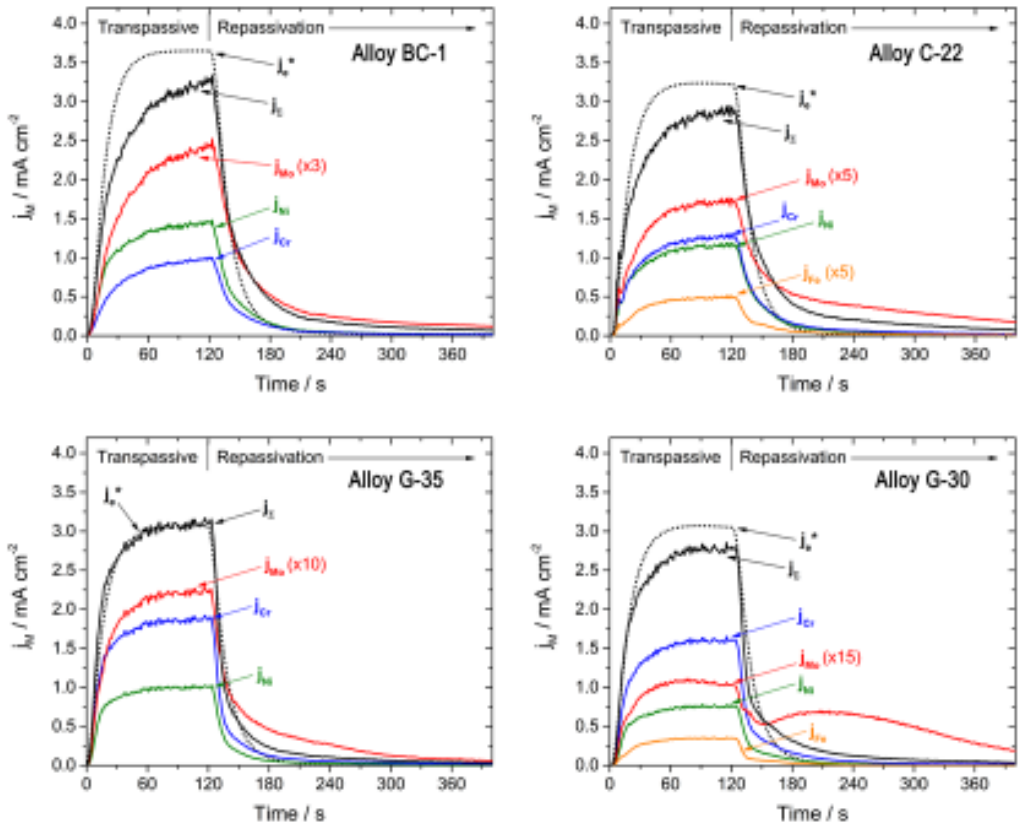
Figure 5. Normalized dissolution rates of alloy G-30 in $1 \mathrm{M} \mathrm{NaCl}$ at $75^{\circ} \mathrm{C}$ with varied times polarized in the transpassive region, identified as step 2.

All dissolution rates are normalized against the bulk material, $\mathrm{Ni}$
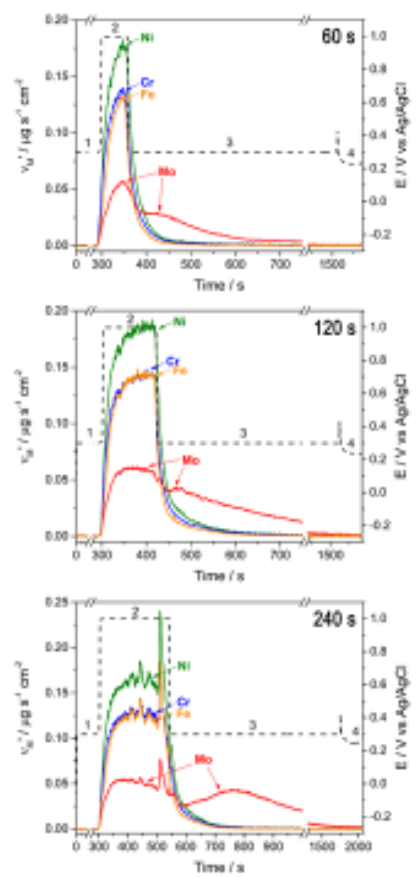
Figure 6. Comparison of the enrichment and dissolution of Mo species during transpassive dissolution and repassivation of alloy G-30, respectively. (A) graphical depiction of areas considered as enrichment / dissolution of molybdenum species. (B) Comparison of enrichment and dissolution as a function of time polarized in the transpassive region.
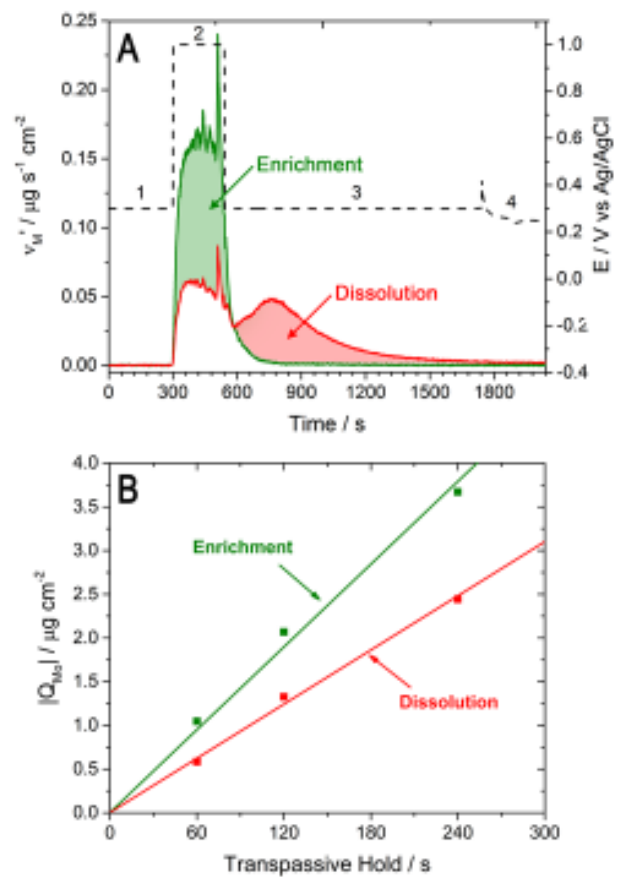
Figure 7. Solubility of $\mathrm{Mo}(\mathrm{VI}), \mathrm{MoO}_{4}{ }^{2-}$, as a function of $\mathrm{pH}$. Calculation done for a $\left[\mathrm{MoO}_{4}{ }^{2-}\right]$ of $1 \mathrm{~mol} \mathrm{~L}^{-}$ ${ }^{1}$, however, the dotted line indicates how solubility is anticipated to change as concentration increases. Data reproduced from Hydra-Medusa software.

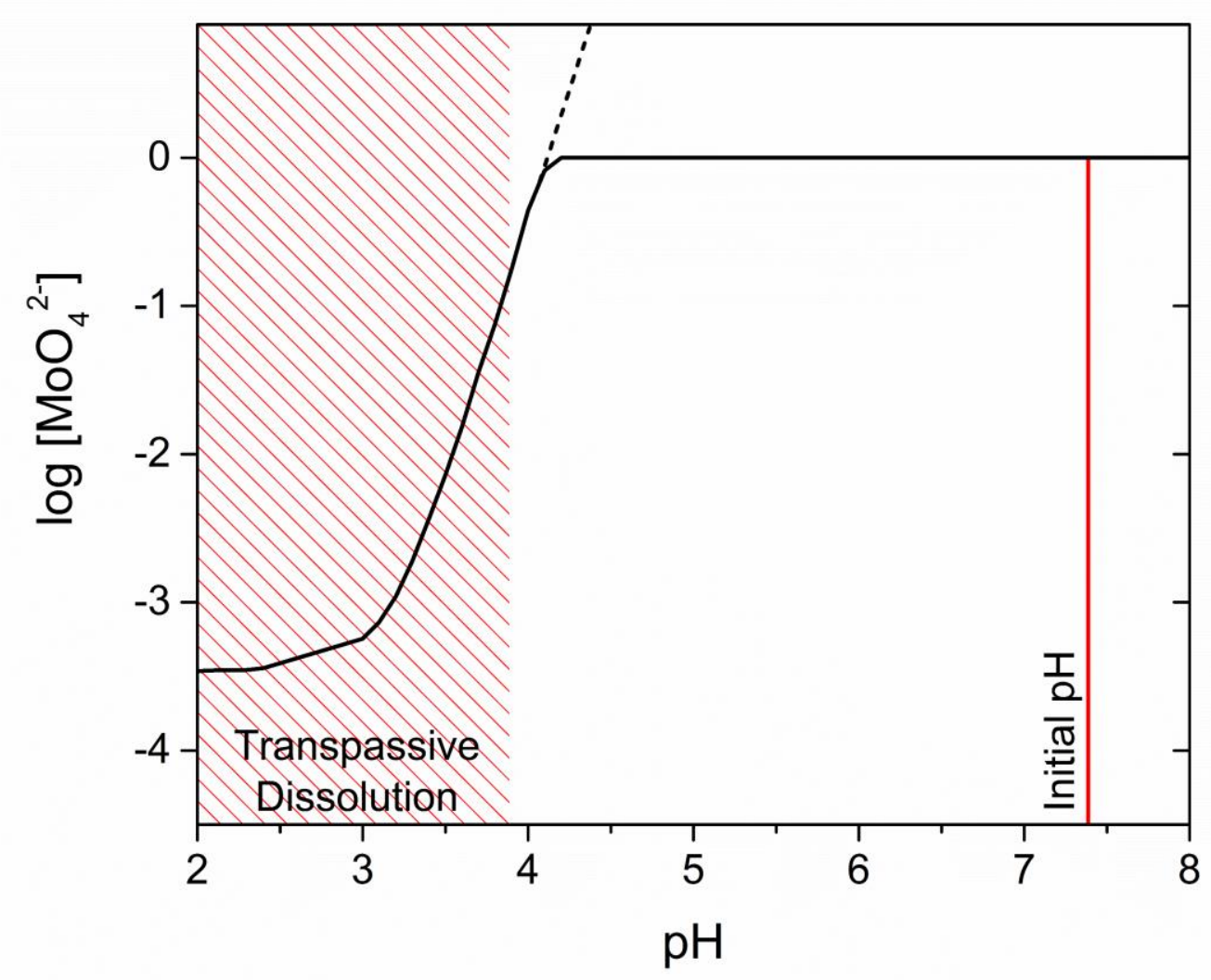


Figure 8. Graphical representation of the surface enrichment during the onset of transpassive dissolution and subsequent release of Mo species during the repassivation of $\mathrm{Ni}$-based alloys.

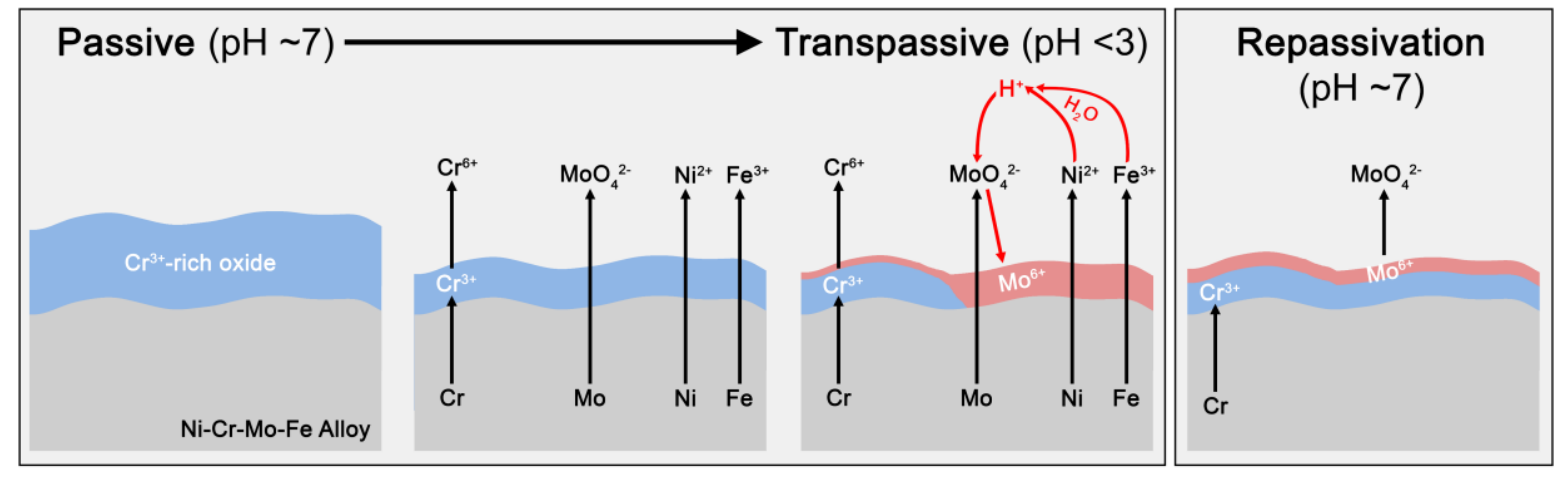


Table 1. Nominal compositions (wt.\%) as reported by Haynes International. M indicates the maximum concentration of an individual alloying element, while, Bal. indicates the alloying element making up the balance due to fluctuations in composition.

\begin{tabular}{|l|l|l|l|l|l|l|l|l|l|l|l|l|l|}
\hline Alloy & $\mathbf{N i}$ & $\mathbf{C r}$ & $\mathbf{M o}$ & $\mathbf{F e}$ & $\mathbf{W}$ & $\mathbf{C u}$ & $\mathbf{N b}$ & $\mathbf{C o}$ & $\mathbf{M n}$ & $\mathbf{V}$ & $\mathbf{A l}$ & $\mathbf{S i}$ & $\mathbf{C}$ \\
\hline BC-1 & Bal. & 15 & 22 & $2^{\mathrm{M}}$ & - & - & - & - & 0.25 & - & $0.5^{\mathrm{M}}$ & $0.08^{\mathrm{M}}$ & $0.01^{\mathrm{M}}$ \\
\hline C-22 & Bal. & 22 & 13 & 3 & 3 & $0.5^{\mathrm{M}}$ & - & $2.5^{\mathrm{M}}$ & $0.5^{\mathrm{M}}$ & $0.35^{\mathrm{M}}$ & - & $0.08^{\mathrm{M}}$ & $0.01^{\mathrm{M}}$ \\
\hline G-35 & Bal. & 33.2 & 8.1 & $2^{\mathrm{M}}$ & 0.6 & $0.3^{\mathrm{M}}$ & - & $1^{\mathrm{M}}$ & $0.5^{\mathrm{M}}$ & - & $0.4^{\mathrm{M}}$ & $0.6^{\mathrm{M}}$ & $0.05^{\mathrm{M}}$ \\
\hline G-30 & Bal. & 30 & 5.5 & 15 & 2.5 & 2 & 0.8 & 5 & 1.5 & - & - & $0.8^{\mathrm{M}}$ & $0.03^{\mathrm{M}}$ \\
\hline
\end{tabular}

Table 2. Alloy composition (wt.\%) as obtained by GD-OES compositional analysis.

\begin{tabular}{|l|l|l|l|l|l|l|l|l|l|l|l|l|l|}
\hline Alloy & $\mathbf{N i}$ & $\mathbf{C r}$ & $\mathbf{M o}$ & $\mathbf{F e}$ & $\mathbf{W}$ & $\mathbf{C u}$ & $\mathbf{N b}$ & $\mathbf{C o}$ & $\mathbf{M n}$ & $\mathbf{V}$ & $\mathbf{A l}$ & $\mathbf{S i}$ & $\mathbf{C}$ \\
\hline BC-1 & 59.7 & 16.53 & 22.28 & 0.76 & 0.01 & 0.007 & 0.03 & 0.17 & 0.27 & 0.02 & 0.19 & $<0.01$ & $<0.01$ \\
\hline C-22 & 52.7 & 25.14 & 13.8 & 3.79 & 3.09 & 0.04 & 0.03 & 0.65 & 0.25 & 0.20 & 0.20 & 0.02 & 0.01 \\
\hline G-35 & 52.7 & 36.53 & 8.52 & 0.78 & 0.04 & 0.01 & 0.051 & 0.38 & 0.45 & 0.04 & 0.23 & 0.22 & 0.05 \\
\hline G-30 & 38.03 & 31.4 & 5.46 & 15.89 & 2.78 & 1.77 & 0.81 & 2.1 & 1.21 & 0.06 & 0.16 & 0.24 & 0.014 \\
\hline
\end{tabular}

Table 3. Experimental emission lines and limits of detection.

\begin{tabular}{|l|l|l|l|}
\hline Element & Wavelength $/ \mathrm{nm}$ & $\begin{array}{l}\text { Detection Limit, } \mathbf{C}_{\mathbf{3 \sigma}} \\
/ \mathrm{ppb}\end{array}$ & Equivalent, $\mathbf{j}_{\mathbf{M}} / \mu \mathrm{A}$ \\
\hline $\mathrm{Ni}$ & 231.60 & 22.8 & 1.9 \\
\hline $\mathrm{Cr}$ & 267.72 & 10.0 & 0.93 \\
\hline $\mathrm{Mo}$ & 202.03 & 4.61 & 0.23 \\
\hline $\mathrm{Fe}$ & 259.94 & 9.40 & 0.81 \\
\hline
\end{tabular}

Table 4. Approximate potential of zero current on the forward scan, $E_{j=0}$, and passive current density, $j_{\text {pass }}$ estimated at $0.200 \mathrm{~V} v \mathrm{Ag} / \mathrm{AgCl}$. Values are averaged over repeat experiments.

\begin{tabular}{|l|l|l|}
\hline & $\mathbf{E}_{\mathrm{j}=0} / \mathrm{V}$ & $\mathbf{j}_{\text {pass }} / \mathrm{A} \mathrm{cm}^{-2}$ \\
\hline BC-1 & -0.090 & $3.4 \times 10^{-6}$ \\
\hline C-22 & 0.019 & $1.9 \times 10^{-6}$ \\
\hline G-35 & 0.066 & $9.7 \times 10^{-7}$ \\
\hline G-30 & 0.076 & $8.6 \times 10^{-6}$ \\
\hline
\end{tabular}

Table 5. Reweighted alloy compositions, considering $\mathrm{Ni}, \mathrm{Cr}, \mathrm{Mo}$, and $\mathrm{Fe}$, and faradaic yields determined for potentiostatic experiments shown in Fig. 3 \& 4.

\begin{tabular}{|c|c|c|c|c|c|c|}
\hline Alloy & Source & $\mathrm{Ni} / \%$ & $\mathrm{Cr} / \%$ & Mo /\% & $\mathrm{Fe} / \%$ & faradaic Yield /\% \\
\hline \multirow{3}{*}{ BC-1 } & Haynes Int. & 62.6 & 15.2 & 22.2 & -- & \multirow{3}{*}{92.2} \\
\hline & GD-OES & 60.1 & 16.7 & 22.4 & 0.7 & \\
\hline & ICP-AES & 64.6 & 12.7 & 22.6 & 0.5 & \\
\hline \multirow{3}{*}{ C-22 } & Haynes Int. & 59.6 & 23.4 & 13.8 & 3.2 & \multirow{3}{*}{98.4} \\
\hline & GD-OES & 55.2 & 26.3 & 14.5 & 3.9 & \\
\hline & ICP-AES & 62.7 & 20.3 & 13.7 & 3.3 & \\
\hline \multirow{3}{*}{ G-35 } & Haynes Int. & 58.4 & 33.4 & 8.2 & -- & \multirow{3}{*}{95.8} \\
\hline & GD-OES & 53.2 & 37.1 & 8.6 & 0.8 & \\
\hline & ICP-AES & 59.1 & 32.5 & 8.4 & 0.6 & \\
\hline \multirow{3}{*}{ G-30 } & Haynes Int. & 46 & 32.1 & 5.9 & 16.0 & \multirow{3}{*}{105.6} \\
\hline & GD-OES & 41.9 & 34.6 & 6.0 & 17.5 & \\
\hline & ICP-AES & 49.9 & 31.2 & 5.2 & 13.8 & \\
\hline
\end{tabular}

